\title{
RESEARCH
}

Open Access

\section{HIV-1 Nef-induced IncRNA AK006025 regulates CXCL9/10/11 cluster gene expression in astrocytes through interaction with CBP/P300}

Feng Zhou ${ }^{1,2^{*}+}$, Xiaomei $\mathrm{Liu}^{2+}$, Dongjiao Zuo ${ }^{2+}$, Min Xue ${ }^{3+}$, Lin Gao ${ }^{2}$, Ying Yang ${ }^{2}$, Jing Wang ${ }^{2}$, Liping Niu ${ }^{2}$, Qianwen $\mathrm{CaO}^{2}$, Xiangyang $\mathrm{Li}^{2}$, Hui Hua ${ }^{2}$, Bo Zhang ${ }^{2}$, Minmin $\mathrm{Hu}^{2}$, Dianshuai Gao ${ }^{4}$, Kuiyang Zheng²,

Yoshihiro Izumiya ${ }^{5}$ and Renxian Tang $^{2^{*}}$ (D)

\begin{abstract}
Background: HIV-associated neurocognitive disorder (HAND) is a neurodegenerative disease associated with persistent neuroinflammation and subsequent neuron damage. Pro-inflammatory factors and neurotoxins from activated astrocytes by HIV-1 itself and its encoded proteins, including the negative factor (Nef), are involved in the pathogenesis of HAND. This study was designed to find potential IncRNAs that regulate astrocyte functions and inflammation process.

Methods: We performed microarray analysis of IncRNAs from primary mouse astrocytes treated with Nef protein. Top ten IncRNAs were validated through real-time PCR analysis. Gene ontology (GO) and KEGG pathway analysis were applied to explore the potential functions of IncRNAs. RIP and ChIP assays were performed to demonstrate the mechanism of IncRNA regulating gene expression.

Results: There were 638 co-upregulated IncRNAs and 372 co-downregulated IncRNAs in primary astrocytes treated with Nef protein for both $6 \mathrm{~h}$ and $12 \mathrm{~h}$. GO and KEGG pathway analysis showed that the biological functions of top differential-expressed mRNAs were associated with inflammatory cytokines and chemokine. Knockdown of IncRNA AK006025, not AK138360, inhibited significantly CXCL9, CXCL10 (IP-10), and CXCL11 expression in astrocytes treated with Nef protein. Mechanism study showed that AK006025 associated with CBP/P300 was enriched in the promoter of CXCL9, CXCL10, and CXCL11 genes.
\end{abstract}

Conclusions: Our findings uncovered the expression profiles of IncRNAs and mRNAs in vitro, which might help to understand the pathways that regulate astrocyte activation during the process of HAND.

Keywords: HIV-associated neurocognitive disorder, HIV-1, IncRNAs, Astrocytes, Nef, CBP/P300, Inflammation

\footnotetext{
*Correspondence: zhoufeng-xzmc@163.com; tangrenxian-t@163.com

${ }^{\dagger}$ Feng Zhou, Xiaomei Liu, Dongjiao Zuo and Min Xue contributed equally to this work.

${ }^{1}$ Jiangsu Key Laboratory of Brain Disease Bioinformation, Research Center for Biochemistry and Molecular Biology, Xuzhou Medical University, Xuzhou 221004, Jiangsu, People's Republic of China

2Jiangsu Key Laboratory of Immunity and Metabolism, Department of Pathogen Biology and Immunology and Laboratory of Infection and Immunity, Xuzhou Medical University, Xuzhou 221004, Jiangsu, People's Republic of China

Full list of author information is available at the end of the article
}

(c) The Author(s). 2018 Open Access This article is distributed under the terms of the Creative Commons Attribution 4.0 International License (http://creativecommons.org/licenses/by/4.0/), which permits unrestricted use, distribution, and reproduction in any medium, provided you give appropriate credit to the original author(s) and the source, provide a link to the Creative Commons license, and indicate if changes were made. The Creative Commons Public Domain Dedication waiver (http://creativecommons.org/publicdomain/zero/1.0/) applies to the data made available in this article, unless otherwise stated. 


\section{Background}

Human immunodeficiency virus type 1 (HIV-1) infection has been demonstrated to be associated with HIV-associated neurocognitive disorders (HAND) that is characterized by degenerative loss of neurons and ultimately develops into HIV-associated dementia (HAD), the most severe form of HAND [1, 2]. Despite the use of highly active antiretroviral therapy (HAART) has successfully prevented many of the former end-stage complications of acquired immunodeficiency syndrome (AIDS), neuronal cell death remains a problem that is frequently found in the brains of HIV-1-infected patients. With prolonged survival of AIDS patients, the prevalence of minor cognitive motor disorder appears to be rising among AIDS patients. Furthermore, HAD is still prevalent in treated AIDS patients.

HAND pathogenesis is associated with the direct and indirect effects of HIV-1 infection on the neuron damage and loss [3]. The direct effects from HIV-1 infection in the central nervous system (CNS) are from the neurotoxicity of HIV-1 itself [4-6] and HIV-1-encoded proteins including gp120 [7-10], transactivator of transcription (Tat) $[3,11-14]$, and negative factor (Nef) $[15,16]$, whereas the indirect toxicity is due to altered glutamate neurotransmission [5], as well as pro-inflammatory cytokines that are secreted by astrocytes or microglia infected with HIV-1 or stimulated with HIV-1 proteins [3, 17].

Astrocytes, the major glial cell type within the CNS [18], support neuron function through promoting formation and function of synapses and build the formation of the blood-brain barrier (BBB) [19]. Furthermore, astrocytes possess the capacity to interact with the peripheral immune system by recruiting leukocytes and monocytes into the CNS [20]. Reactive astrocytosis is an important feature in an inflammatory condition that occurs during HAND pathology [21]. Experimental data indicate that astrocyte activation is involved in the pathogenesis of HAND characterized by an increased expression of pro-inflammatory cytokines and chemokine $[3,17]$. In response to HIV-1 and its encoded protein, Nef, in the CNS, astrocytes increase chemokine production to facilitate $\mathrm{T}$ cells and monocytes recruitment to the CNS [17]. However, the mechanisms by which astrocyte activation contribute to HAND by Nef remain still unknown.

$\mathrm{Nef}$ is a $27-\mathrm{kDa}$ myristoylated protein released from HIV-infected cells in the exosome manner [22-24]. Nef interacts with a multitude of cellular factors and functions in trafficking, signal transduction, and gene expression. Nef leads to neural cell death directly and indirectly through the production of CXCL10 (IP-10) [25]. Functionally, Nef expressed in astrocytes results in impairing spatial and recognition memory in rats [26]. Clinical data display that Nef expresses in hippocampal neurons in $\mathrm{HIV}^{+}$patients with $\mathrm{HAD}$ [27], consistent with this protein being involved in the memory impairment of those individuals. Of important, HIV-1 Nef induces CCL5 production in astrocytes to promote neuron death through p38-MAPK and PI3K/Akt pathway and utilization of transcription factors, such as NF- $\mathrm{kB}, \mathrm{C} /$ EBP, and AP-1 [16]. These exciting results have prompted us to scan the expression profiles of inflammatory cytokines and chemokine in astrocytes induced by Nef and their roles in HAND pathogenesis.

Long non-coding RNAs (lncRNAs) have been defined as RNA transcripts more than 200 nucleotides in length that do not encode proteins. Based on the IncRNA-related position in the genome to the protein-coding genes, IncRNAs include five categories, which are sense, antisense, intronic, intergenic, and bidirectional [28]. Emerging evidence suggests that they play key roles in various biological and physiological processes including chromatin remodeling, epigenetic regulation, RNA splicing, and protein transport and directly relate to human diseases including neurodegenerative disorders [29-32]. One of the major functions of lncRNAs appears to be in the epigenetic regulation of gene transcription [32]. For example, lncRNAs have been shown to associate with a plethora of epigenetic modifier complexes including PRC2, PRC1, Cbx1, Cbx3, Tip60/P400, Setd8, ESET and Suv39h1, Jarid1b, Jarid1c, HDAC1, and YY1 [33, 34]. It has been reported that IncRNA H19 promotes neuroinflammation in ischemic stroke by driving HDAC1-dependent M1 microglial polarization [35]. In addition, IncRNAs activate NF- $\mathrm{KB}$ and MAP kinase pathway to regulate inflammation gene expression [36-39]. However, the roles of lncRNAs in the process of HAND are still unknown.

CREB-binding protein (CBP)/P300, histone acetyltransferase (HAT), is transcription co-activator that is cis-regulatory elements to control patterns of gene expression. By the enzymatic activity localized in HAT domain, CBP/P300 target both histones and numerous transcriptional factors (TFs), leading to elevated histone 3 lysine 27 acetylation (H3K27ac), p53, NF-kB, and RNA Pol II acetylation that forms a transcription network "hub" to promote gene expression [40-45]. Recent data show that CBP/P300 binds directly to enhancer RNAs (eRNAs) to stimulate histone acetylation and gene transcription [46]. Moreover, lncRNAs bind CBP/P300 activity to regulate gene expression [47].

In the present study, we analyzed the IncRNA and mRNA expression landscape of astrocytes treated by Nef protein in vitro. Our results suggest potential roles of lncRNAs in regulating inflammation in astrocytes during the process of HAND.

\section{Methods \\ Animals}

C57BL/6 mice were obtained from Nanjing University Laboratory Animal Center. Mice were housed at $25 \pm 1^{\circ}$ 
$C$ with 55-65\% humidity and maintained under specific pathogen-free conditions. All experimental procedures described in our study were performed according to the Provision and General Recommendation of the Chinese Laboratory Association. The protocol was approved by the Institutional Animal Care and Use Committee of Xuzhou Medical University.

\section{Primary astrocyte culture}

Primary mouse astrocytes from 0- to 1-day-old C57BL/6 mice were established as previously described [48]. In brief, the cerebral cortices freed of meninges were dissected, minced, and digested. After washed twice in DMEM/F12 medium containing 10\% fetal bovine serum (FBS), the cells were filtrated, transferred to culture flasks pre-coated with $1 \mathrm{mg} / \mathrm{ml}$ poly-L-lysine (Sigma), and then cultured at $37{ }^{\circ} \mathrm{C}$ with $5 \% \mathrm{CO}_{2}$. Cells were passed for three passages and then glial fibrillary acidic protein (GFAP, astrocytic marker) expression was analyzed using immunofluorescence assays (IFA). Finally, at least 95\% $\mathrm{GAFP}^{+}$cells were used to research.

Primary human astrocytes were obtained from ScienCell Research Laboratories with the help of Shanghai Zhong Qiao Xin Zhou Biotechnology Co., Ltd. in China. Human astrocytes were cultured in the Astrocyte Medium (AM, Cat. No. 1801) contained 2\% FBS (Cat. No. 0010) and astrocyte growth supplement (AGS, Cat. No. 1852) at $37^{\circ}$ $\mathrm{C}$ with $5 \% \mathrm{CO}_{2}$. Cells were passed for three passages and performed to research.

\section{RNA extraction}

Total RNA was extracted from the primary astrocytes according to manufactures instructions. RNA quantity and quality was measured using NanoDrop ND-1000 spectrophotometer (Thermo Fisher Scientific).

\section{Determination of IncRNA and mRNA profiles}

The expression profiles of lncRNAs and mRNAs were detected as previously described [49]. Primary mouse astrocytes treated with $50 \mathrm{ng} / \mathrm{ml}$ Nef protein (Abcam, ab90462) were detected using Mouse LncRNA Microarray v2.0 ( $8 \times$ $60 \mathrm{~K}$, Arraystar) by Kangchen Bio-tech (Shanghai, China) that designed for the global profiling of mouse LncRNAs and protein-coding transcripts. Thirty-one thousand four hundred twenty-three LncRNAs and 25,376 coding transcripts can be detected by the second-generation LncRNA microarray. The LncRNAs are carefully collected from the most authoritative databases such as RefSeq, UCSC Known Genes, Ensembl, and many related literatures. Each transcript is represented by a specific exon or splice junction probe which can identify accurately individual transcript. Positive probes for housekeeping genes and negative probes are also printed onto the array as hybridization quality control.
According to previous experimental project, microarray assays had also been performed using pooled plasma, blood, liver, heart, or cell samples [50]. RNAs from mixed astrocytes treated with Nef protein three times were run microarray analysis. The acquired raw array images were processed by Agilent Feature Extraction software (version 11.0.1.1) and then normalized and analyzed by the GeneSpring GX v12.0 software package (Agilent Technologies). Differentially expressed lncRNAs and mRNAs were then identified through fold change as well as $P$ values calculated with $t$ test. The threshold for up and downregulation was fold change $>2.0$ and $P$ value $<0.05$. Afterwards, hierarchical clustering was performed to display the distinguishable IncRNA and mRNA expression patterns among the samples.

\section{Real-time PCR assay}

Real-time PCR (real-time PCR) assay was detected as previously described [49]. In brief, the total RNA from cultured astrocytes was extracted with TRIzol reagent (Invitrogen). First-strand cDNAs were generated using PrimeScriptTM RT reagent kit (TaKaRa, Japan), and SYBR Premix Ex TaqTM based on real-time PCR (TaKaRa) was performed to analyze the relative expression levels of lncRNAs and mRNAs. The relative gene expression was calculated using the $2^{-\triangle \Delta C T}$ method. The primers are listed in Additional file 1: Table S1.

\section{Functional group analysis of mRNAs}

Gene ontology (GO) and KEGG analysis were applied to determine the functions of differentially expressed mRNAs in biological pathways using the standard enrichment computation method [49]. The $P$ value (hypergeometric $P$ value) denotes the significance of the pathway correlated to the conditions. The recommend $P$ value cutoff is 0.05 .

\section{ELISA}

The levels of Cxcl9, Cxcl10, and Cxcl11 in the supernatants of cultured astrocytes were detected using Mouse ELISA kits (Abcam) according to the manufacturer's instructions.

\section{RNA immunoprecipitation (RIP) assay}

RIP assay was performed as previously described [51].In brief, after treated with Nef protein, $2 \times 10^{7}$ primary mouse astrocytes were treated with $0.3 \%$ formaldehyde in DMEM/F12 medium for $10 \mathrm{~min}$ at $37^{\circ} \mathrm{C}$. Glycine dissolved in PBS $(1.25 \mathrm{M})$ was added to the final concentration of $0.125 \mathrm{M}$ for $5 \mathrm{~min}$ at room temperature (RT). Cells were then washed twice in cold PBS and pelleted. The pellets were resuspended in RIPA buffer and incubated on ice with frequent vortex for $30 \mathrm{~min}$, and the lysate was centrifugated at 13,000 RPM for $10 \mathrm{~min}$. 
Antibodies $(5 \mu \mathrm{g})$ were added and incubated for $4 \mathrm{~h}$ at $4^{\circ}$ C. Samples were washed twice in RIPA buffer, four times in 1 M RIPA buffer, and then twice in RIPA in spin columns. The beads were resuspended in RIPA buffer and treated with proteinase $\mathrm{K}$ at $45{ }^{\circ} \mathrm{C}$ for 45 min. RNA samples were extracted with Trizol. Co-precipitated RNAs were purified with the RNeasy Mini Kit (QIAGEN) and detected by real-time PCR. The data of retrieved RNAs is calculated from the subtraction of $\mathrm{RT} /$ input ratio and non-RT/input ratio. The primer sequence was listed in Additional file 1: Table S1.

\section{Chromatin immunoprecipitation (ChIP) assay}

ChIP assays were performed as described previously [52]. Briefly, primary mouse astrocytes were treated with or without Nef protein for $3 \mathrm{~h}$. Cells were cross-linked with $1 \%$ formaldehyde (final concentration) for $10 \mathrm{~min}$ at RT and then stopped by $1.25 \mathrm{mM}$ of glycine (final concentration). $1 \times 10^{7}$ cells were used for each ChIP-enrichment. Chromatin was sheared to the fragment size of 200500 bp using a Bioruptor (Diagenode). The antibodies used in the ChIP experiments were anti-NF-kB p65 antibody (Cell Signaling Technologies), anti-H3K27ac antibody (Abcam), anti-RNA Pol II antibody (Active Motif),
anti-CBP/P300 antibody (Cell Signaling Technologies), normal mouse IgG (Santa Cruz). All immunoprecipitated chromatin DNA was analyzed by real-time PCR. The primer sequences were listed in Additional file 1: Table S1.

\section{Knockdown of IncRNAs}

To silence the mouse lncRNA AK006025 and AK138360, siRNA sequences against AK006025 and AK138360 were designed. siRNA sequences were as follows: si-Ctrl, 5'-UUC UCC GAA CGU GUC ACG UTT-3'; siAK006025, 5' -GCT GGG AAC CCA CAC ATA A-3' and si-AK138360, 5'-GCA CCG GGC AAT GTT TAA T-3'.

\section{Statistical analysis}

SPSS version 18.0 was used for the statistical analysis of experimental data. Data presented as mean \pm standard error of mean (SEM), calculated for all points from at least three independent experiments in triplicates. Statistical significance was determined using the two-tailed Student's $t$ test or by one-way analysis of variance (ANOVA) when more than two groups were compared. $P<0.05$ was considered significant.
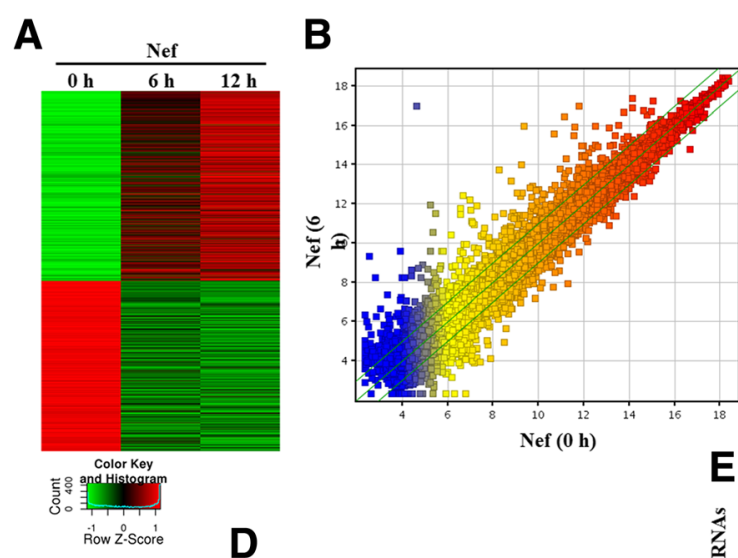

D

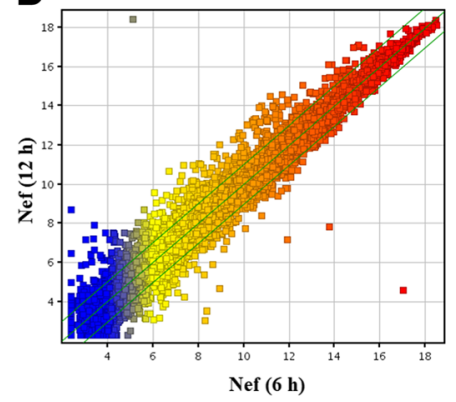

C
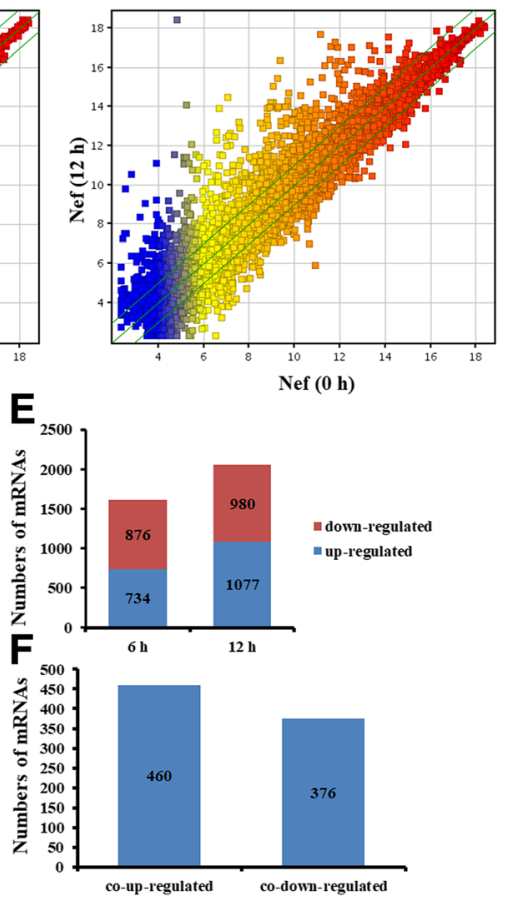

Fig. 1 Identification of differentially expressed mRNAs in primary mouse astrocytes treated with Nef protein. a Heatmap of mRNAs significantly changed upon Nef $(50 \mathrm{ng} / \mathrm{ml})$ stimulation of astrocytes. b, c, d Scatter plot compared global mRNA gene expression profiles in Neftreated astrocytes. The values of $\mathrm{X}$-axis and $\mathrm{Y}$-axis in the scatter plot were the normalized signal values of each sample (log2 scaled). The green lines are fold change (the default fold change value given is 2.0). The mRNAs above the top green line and below the bottom green line indicate more than 2.0-fold change, compared to the control. e Analysis of numbers of significantly expressed mRNAs. $\mathbf{f}$ Overlapped and differentially expressed mRNAs 


\section{Results}

Differentially expressed mRNA in the primary mouse astrocytes treated with Nef protein

To detect differentially expressed mRNAs in the activated mouse primary astrocytes, we performed a genome-wide analysis of mRNA expression profiles in the astrocytes stimulated with Nef protein $(50 \mathrm{ng} / \mathrm{ml})$ at the different time point (Fig. 1a). Firstly, a graphical overview of the expression signatures of mRNAs was performed by scatter plot analyses. The result displayed that a great number of mRNAs were differentially expressed in the astrocytes with Nef protein at 0 h, 6 h, and 12 h (Fig. 1b, c). Meanwhile, many mRNAs were differentially co-expressed in the astrocytes with Nef protein at $6 \mathrm{~h}$ and $12 \mathrm{~h}$ (Fig. 1d).

We then analyzed altered expression of mRNAs with fold change $>2$, the criteria $P$ value $<0.05$ in the astrocytes stimulated by Nef protein at $6 \mathrm{~h}$ and $12 \mathrm{~h}$ compared with $0 \mathrm{~h}$, respectively. Results showed that 734 mRNAs were upregulated, and 876 mRNAs were downregulated in the astrocytes stimulated by Nef protein for $6 \mathrm{~h}$ (Fig. 1e) and that 1077 upregulated and 980 downregulated mRNAs for $12 \mathrm{~h}$ (Fig. 1e). Notably, there were 460 co-upregulated and 376 co-downregulated mRNAs for between $6 \mathrm{~h}$ and $12 \mathrm{~h}$ (Fig. 1f). Importantly, there were many inflammatory cytokines and chemokine,

Table 1 Top 20 overlapped and upregulated mRNAs in mouse astrocytes treated with Nef protein $(50 \mathrm{ng} / \mathrm{ml})$ for $6 \mathrm{~h}$ and $12 \mathrm{~h}$

\begin{tabular}{lll}
\hline Gene symbol & \multicolumn{2}{l}{ Upregulated folds } \\
\cline { 2 - 3 } & $6 \mathrm{~h} / \mathrm{h}$ & $12 \mathrm{~h} / \mathrm{h} \mathrm{h}$ \\
\hline Cxcl11 & 105.05796 & 473.09506 \\
Cxcl9 & 43.443104 & 213.93571 \\
Ifnb1 & 112.73581 & 154.63144 \\
II1b & 54.497185 & 153.78612 \\
Gm4841 & 52.749744 & 149.3729 \\
Cxcl2 & 98.37795 & 131.17091 \\
Irg1 & 69.53818 & 101.9587 \\
Ccl5 & 39.71899 & 94.32046 \\
II6 & 21.031158 & 74.925606 \\
Ccl7 & 27.82146 & 74.49636 \\
Fam26f & 11.689228 & 64.880646 \\
Cd69 & 30.492313 & 53.828453 \\
Cxcl10 & 37.51984 & 45.796886 \\
Cxcl1 & 20.680431 & 45.20861 \\
II1a & 13.884002 & 49.921574 \\
Cxcl3 & 38.239742 & 43.34039 \\
Tnfsf10 & 4.3851957 & 24.53629 \\
Tnf & 30.36271 & 24.412766 \\
Ccl3 & 11.2570715 & 15.065439 \\
Ccl2 & 9.46433 & 10.722074 \\
\hline
\end{tabular}

especially highly expressed Cxcl11, Cxcl10 (IP-10), Cxcl9, Cxcl3, Cxcl2, Cxcl1, Ccl5, Il-1 $\beta$, Il-6, and Tnf, among the co-upregulated mRNAs (Table 1).

To confirm the role of Nef protein in chemokine expression in human astrocytes, human primary astrocytes were treated with Nef protein for $6 \mathrm{~h}, C X C L 9, C X C L 10$, and CXCL11 mRNA levels were determined by real-time PCR assay. The results showed that mRNA levels of CXCL9, CXCL10, and CXCL11 were significantly increased in human astrocytes treated with Nef at $6 \mathrm{~h}$ and $12 \mathrm{~h}$ (Fig. 2a), which was inconsistent with mouse astrocytes. To further determine upregulated mouse Cxcl9, Cxcl10, and Cxcl11 by soluble recombinant Nef protein rather than by other factors like lipopolysaccharide (LPS), mouse primary astrocytes were immunoeluted with Nef (iNef) protein through using anti-Nef antibody (Abcam, ab42355) pretreatment prior to Nef stimulation for $6 \mathrm{~h}$. Real-time PCR assay indicated that iNef did not induce mRNA levels of $C x c l 9, C x c l 10$, and $C x c l 11$ (Fig. 2b). These results suggest that Nef itself enhances CXCL11, CXCL10, and CXCL9 expression in human and mouse astrocytes.

\section{Go and KEGG pathway analysis of the molecular function of differentially expressed genes}

To further explore potential molecular mechanism in HAND pathogenesis, GO and KEGG pathway analysis was performed for differentially expressed genes in astrocytes treated with Nef protein. GO analysis showed that the molecular function (MF) of differentially co-upregulated expressed transcripts was associated with cytokine and chemokine activity as well as their receptor binding in astrocytes treated with Nef protein (Fig. 3a). Furthermore, differentially co-downregulated genes were mainly related with protein binding in astrocytes treated with Nef protein (Fig. 3b).

KEGG pathway analysis indicated that 40 pathways were significantly involved in differentially expressed genes. Upregulated genes were enriched in cytokine and its receptor interaction, chemokine signaling pathway, NF- $\mathrm{kB}$ signaling pathway, and so on (Fig. 3c). Downregulated genes were involved in metabolism, lysosome, CoA biosynthesis, insulin signaling pathway, etc. (Fig. 3d). The above data represent that HAND is associated with the mRNA changes of inflammatory factors in the astrocytes.

\section{Differentially expressed IncRNA in the primary mouse astrocytes treated with Nef protein}

We further determined differentially expressed lncRNAs in the astrocytes treated with Nef protein at the different time point (Fig. 4a). Scatter plot analyses were firstly used to scan the expression signatures of lncRNAs. The result showed that a large number of lncRNAs were differentially expressed in the astrocytes with Nef protein at $0 \mathrm{~h}, 6 \mathrm{~h}$, and $12 \mathrm{~h}$ (Fig. 4b, c). Meanwhile, lots of 

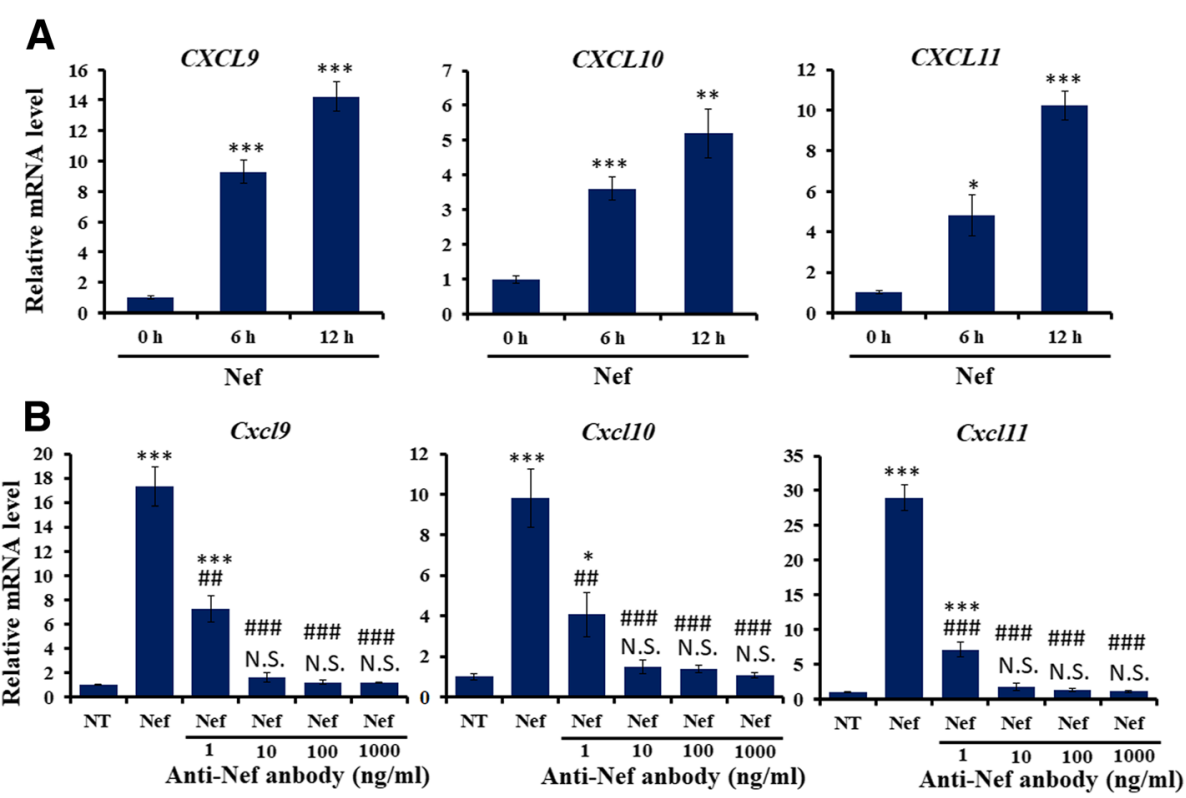

Fig. 2 Determination of effects of Nef protein on CXCL9/10/11 gene expression. a Primary human astrocytes were treated with soluble Nef protein $(50 \mathrm{ng} / \mathrm{ml})$ for $6 \mathrm{~h}$ and $12 \mathrm{~h}$. Human CXCL9, CXCL10, and CXCL11 mRNA levels were determined by real-time PCR assay $(n=$ 3). Error bars represent means \pm SEM. ${ }^{*} P<0.05$, ${ }^{*} P<0.01$, ${ }^{* * *} P<0.001$, vs 0 h. b Primary mouse astrocytes were pre-treated with different concentration of anti-Nef antibody followed by soluble Nef protein $(50 \mathrm{ng} / \mathrm{ml})$ for $6 \mathrm{~h}$. Mouse Cxcl9, Cxcl10, and Cxcl11 mRNA levels were

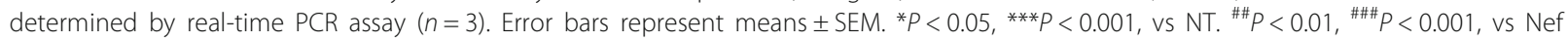

lncRNAs were differentially expressed in the astrocytes with Nef protein at $12 \mathrm{~h}$, compared to $6 \mathrm{~h}$ (Fig. $4 \mathrm{~d}$ ).

We then analyzed the differential expression of IncRNAs in the astrocytes stimulated by Nef protein at $6 \mathrm{~h}$ and $12 \mathrm{~h}$ compared with $0 \mathrm{~h}$, respectively. Results showed that 1358 lncRNAs were upregulated, and 670
lncRNAs were downregulated in the astrocytes stimulated by Nef protein for $6 \mathrm{~h}$ (Fig. 4e) and that 1534 upregulated and 1271 downregulated IncRNAs for $12 \mathrm{~h}$ (Fig. 4e). Notably, there were 638 co-upregulated and 372 co-downregulated lncRNAs for both $6 \mathrm{~h}$ and $12 \mathrm{~h}$ (Fig. 4f). The list of the top 20 differentially expressed
A

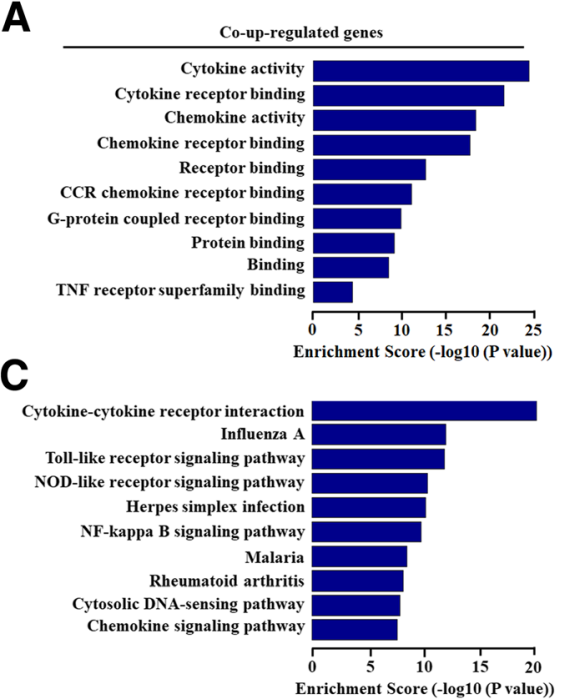

B
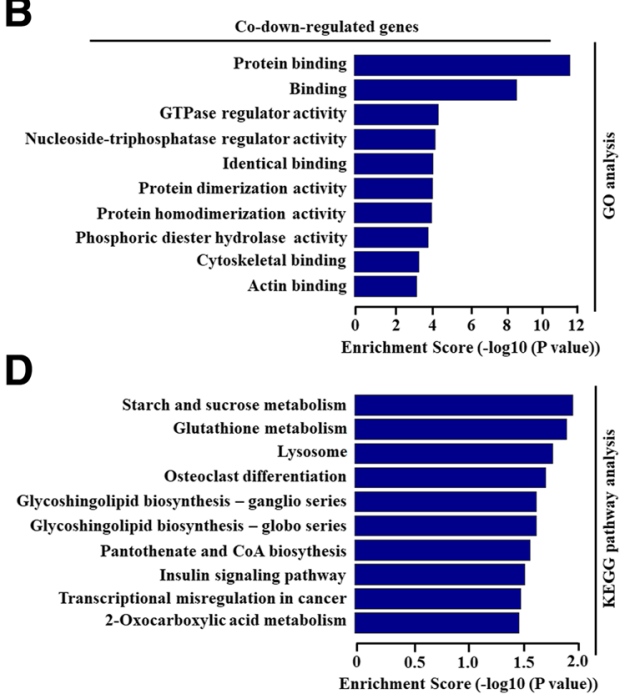

Fig. 3 Biological function of differentially overlapped genes with fold changes more than 2.0. a $\mathbf{b}$ GO analysis of significant molecular function of co-upregulated and co-downregulated genes were shown in primary mouse astrocytes treated by Nef protein $(50 \mathrm{ng} / \mathrm{ml})$ with $6 \mathrm{~h}$ and $12 \mathrm{~h}$. c, $\mathbf{d}$ KEGG pathway analysis of significant pathways for co-upregulated and co-downregulated genes were shown in primary mouse astrocytes treated by Nef protein with $6 \mathrm{~h}$ and $12 \mathrm{~h}$ 

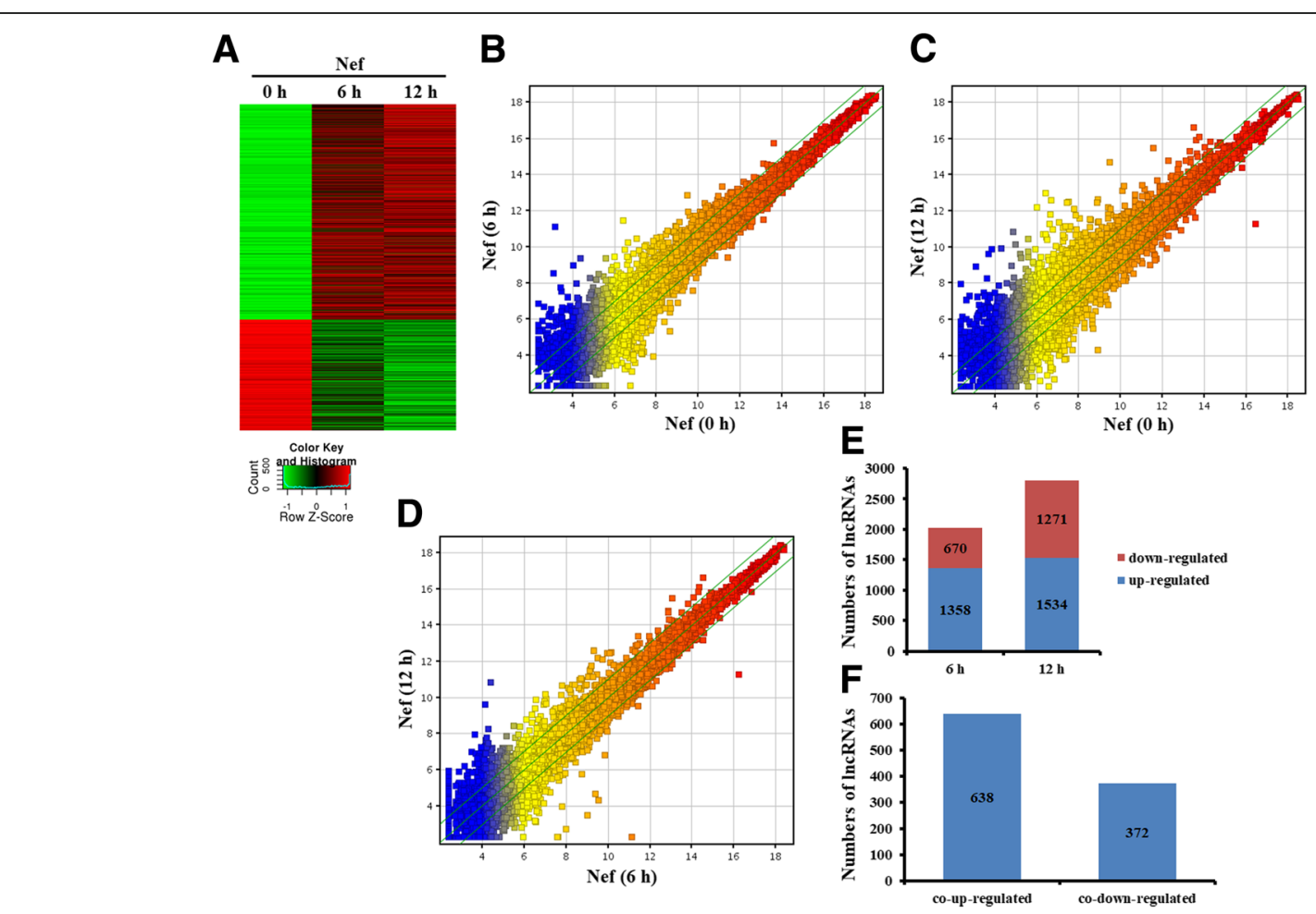

C

Fig. 4 Analysis of differentially expressed IncRNAs in primary mouse astrocytes treated with Nef protein. a Heatmap of lincRNAs significantly changed upon Nef $(50 \mathrm{ng} / \mathrm{ml})$ stimulation of astrocytes. b, c, d Scatter plot compared global IncRNA expression profiles in Nef-treated astrocytes. The values of $\mathrm{X}$-axis and $\mathrm{Y}$-axis in the scatter plot were the normalized signal values of each sample (log2 scaled). The green lines are fold change (the default fold change value given is 2.0). The mRNAs above the top green line and below the bottom green line indicate more than 2.0-fold change, compared to the control. e Analysis of numbers of significantly expressed IncRNAs. f Overlapped and differentially expressed IncRNAs

lncRNAs for both $6 \mathrm{~h}$ and $12 \mathrm{~h}$ identified by microarray analysis was shown in Additional file 1: Table S2 and Table 2.

\section{Validation of the microarray data using real-time PCR}

To further verify the accuracy of microarray data, we randomly assigned 10 lncRNAs from the differentially expressed lncRNAs, including 5 co-upregulated (Gm16685, Gm12250, AK151815, AK139352, and Gm8773) and 5 co-downregulated (AK038606, Gm12326, AK039511, Gm13484, and AK043126) and tested their expression through real-time PCR assay. As shown in Fig. 5, Gm16685, Gm12250, AK151815, AK139352, and Gm8773 expression were significantly increased, whereas AK038606, Gm12326, AK039511, Gm13484, and AK043126 expression were obviously decreased in the astrocytes stimulated by Nef protein for $6 \mathrm{~h}$ and $12 \mathrm{~h}$, compared with $0 \mathrm{~h}$. Overall, these data confirmed the accuracy of microarray data.

\section{Analysis of upregulated IncRNAs on the chromosome 5 in} the primary mouse astrocytes treated with Nef protein Then, we analyze differentially co-upregulated lncRNAs on chromosome 5 in the primary mouse astrocytes treated with Nef protein for $6 \mathrm{~h}$ and $12 \mathrm{~h}$. As shown in
Table 2, ten lncRNAs were selected as targeted ones. All of them were located at two terminals of $\mathrm{Cxcl} 3 / 2 / 1$ gene cluster and $\mathrm{Cxcl} / 10 / 11$ gene cluster (Additional file 1: Table S2). Among them, Uc008xxt.1 and AK138360 were close to $5^{\prime}$ terminal of $\mathrm{Cxcl} 3 / 2 / 1$ gene cluster while AK148399 and AK006025 were nearby the $3^{\prime}$ terminal of the Cxcl9/10/11 gene cluster (Fig. 6a). The class distribution of AK138360 and AK006025 were intergenic, Uc008xxt.1 was sense-overlap, and AK148399 was bidirectional (Additional file 1: Table S3).

We further measured above lncRNAs expression by real-time PCR in primary astrocytes stimulated with Nef protein. Results of real-time PCR showed that Uc008xxt.1, AK138360, AK148399, and AK006025 were significantly regulated (Fig. 6b), which was in accordance with the microarray data.

\section{Knockdown of IncRNA AK006025 repressed Cxcl9/10/11 cluster gene expression}

Intergenic lncRNA, as an in cis-regulatory element, regulates gene expression. To determine the role of intergenic lncRNAs in regulating $\mathrm{Cxcl} 9 / 10 / 11$ cluster gene expression, siRNA of AK138360 or AK006025 was transfected into primary mouse astrocytes for $48 \mathrm{~h}$, 
Table 2 Top 20 overlapped and upregulated IncRNAs in mouse astrocytes stimulated with Nef protein $(50 \mathrm{ng} / \mathrm{ml})$ for $6 \mathrm{~h}$ and $12 \mathrm{~h}$

\begin{tabular}{llll}
\hline IncRNA seqname & Length & \multicolumn{2}{l}{ Upregulated folds } \\
\cline { 3 - 4 } & & $6 \mathrm{~h} / \mathrm{O} \mathrm{h}$ & $12 \mathrm{~h} / 0 \mathrm{~h}$ \\
\hline Gm16685 & 1592 & 33.808704 & 98.312874 \\
Gm5970 & 1216 & 11.263321 & 75.315765 \\
Gm12250 & 1274 & 6.2884264 & 61.74965 \\
AK085771 & 1165 & 6.540899 & 66.45514 \\
uc008roq.1 & 3961 & 45.042114 & 58.77 \\
Gm4955 & 913 & 6.5966477 & 50.151352 \\
A530040E14Rik & 1262 & 10.544557 & 50.162678 \\
Gm12407 & 720 & 6.1827254 & 33.648342 \\
Gm13309 & 324 & 6.142315 & 30.465094 \\
Mx2 & 2428 & 12.378684 & 37.599354 \\
AK151815 & 1592 & 7.3327208 & 26.562384 \\
MM9LINCRNAEXON11240- & 1100 & 10.792236 & 20.239393 \\
uC008smk.1 & 701 & 6.23503 & 32.482025 \\
ENSMUST00000160565 & 1414 & 3.362174 & 22.119934 \\
AK139352 & 4337 & 6.970084 & 36.466106 \\
AK145170 & 2791 & 9.817351 & 20.934488 \\
ENSMUST00000135659 & 1443 & 14.289103 & 18.727198 \\
NR_003507 & 1848 & 3.7799745 & 14.091469 \\
Gm8773 & 1268 & 5.3409157 & 10.783084 \\
uc008zif.1 & 704 & 2.7248611 & 12.014651 \\
\hline
\end{tabular}

followed by Nef protein treatment for $6 \mathrm{~h}$ and $12 \mathrm{~h}$, respectively. We detected Cxcl9/10/11 expression using ELISA and real-time PCR. As seen from Fig. 7a, siRNA of AK138360 or AK006025 inhibited their expression. All of Cxcl9, Cxcl10, and Cxcl11 expression were significantly decreased in mouse astrocytes treated with $\mathrm{Nef}$ protein after knockdown of AK006025, not AK138360 (Fig. 7b).

\section{AK006025 associated with CBP/P300 regulates Nef- induced $\mathrm{Cxcl} 9 / 10 / 11$ cluster gene expression}

To further uncover the potential mechanism how lncRNA AK006025 regulated Cxcl9/10/11 cluster gene expression, RIP assay was used for detecting lncRNA AK006025 and NF-kB p65 and/or CBP/P300 interaction. RIP results showed that AK006025 was significantly associated with NF- $\mathrm{kB}$ p65 and CBP/P300 in mouse astrocytes treated with Nef protein for $3 \mathrm{~h}$ (Fig. 8a). Furthermore, ChIP assay indicated that NF- $\mathrm{kB}$ p65, CBP/P300, RNA Pol II, and H3K27ac were differentially enriched in in the promoter $\mathrm{Cxcl} 9 / 10 / 11$ gene cluster in mouse astrocytes treated with Nef protein for $3 \mathrm{~h}$ (Fig. 8b). Of importance, siRNA of AK006025 repressed dramatically NF-kB p65 and CBP/P300 enrichment in the promoter Cxcl9/10/11 gene cluster in mouse astrocytes treated with Nef protein for $3 \mathrm{~h}$ (Fig. 8c). The data suggest that the interaction of AK006025 and CBP/P300 may regulate epigenetically $\mathrm{Cxcl} 9 / 10 / 11$ cluster gene transcription.

\section{Discussion}

HAND is a degenerative disease of the central nervous system with chronic inflammation, synapse dysfunction, and neuron loss. Many studies have determined that the blockade of pro-inflammatory cytokine and chemokine production in astrocytes could protect the neuron damage of HAND pathogenesis [13, 16, 17].

Nef, a myristoylated protein encoded by HIV-1, functions in the multifaceted biological process including trafficking, signal transduction, and gene expression in a paracrine manner. Nef is released from infected cells into the plasma of HIV-infected individuals [53]. The detectable concentration of soluble $\mathrm{Nef}$ in the serum ranges from 1 to $10 \mathrm{ng} / \mathrm{ml}[54,55]$. The soluble Nef can be taken up by several types of cells to regulate cellular function, such as B cells, primary effusion lymphoma (PEL) cells, pulmonary arterial endothelial cells as well as primary human umbilical vein endothelial cells (HUVECs) [56-59]. Although HIV-1 built latency in astrocytes in the brain, the expression of HIV-1 genes are low, for example, HIV p24 in HIV-1 ${ }^{+}$postmortem brain astrocytes is rarely detected [60]. Therefore, we used soluble Nef protein as an exogenous factor to explore its role in inducing the expression of lncRNAs and mRNAs. Here, our data showed that the exogenous Nef protein enhanced CCL5 and IP-10 expression in astrocytes, consistent with previous data of endogenous Nef expression $[16,25]$.

Over the past decades, the molecular mechanisms underlying HAND have been extensively explored. However, the understanding of the pathophysiological process of HAND is still limited. In recent years, a large number of evidence shows that lncRNAs have been associated with human diseases, such as cancer, neurological disorders, and so on $[30,31,52,61]$. LncRNAs are found as important regulators of neurodevelopment and brain function [31]. However, there is no knowledge that lncRNAs are associated with a particular molecular or cellular function in HAND pathogenesis. To date, the functional characterization of lncRNAs during the HAND/HAD process and astrocyte activation has not been uncovered. Our recent study demonstrated the expression profiles of lncRNAs in Nef-treated astrocytes, analyzed the co-expression of lncRNAs in vivo and in vitro, and explored their characteristics and possible relations with protein-coding genes. 

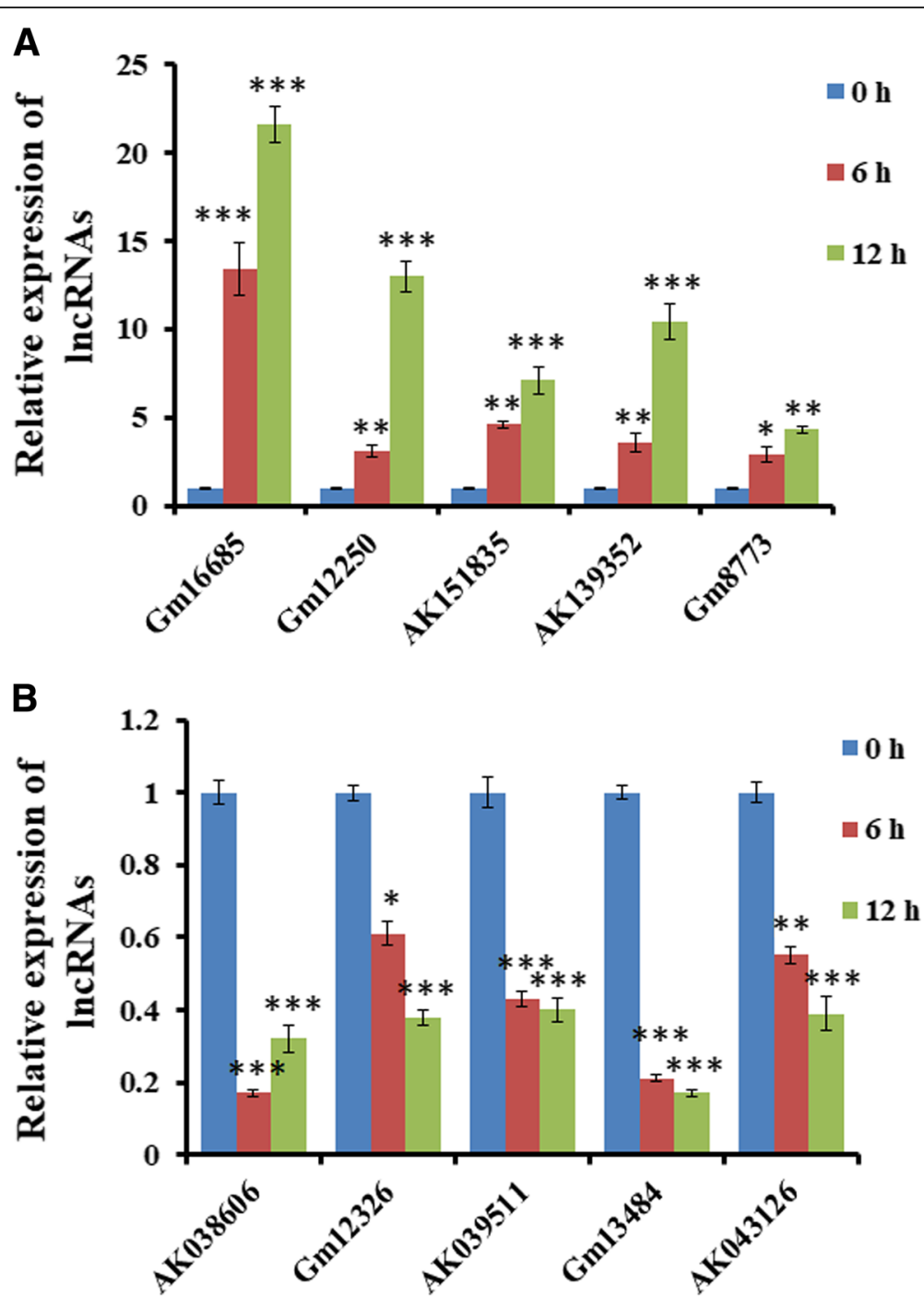

Fig. 5 Real-time PCR verification of differentially co-expressed IncRNAs in astrocytes stimulated with Nef. Ten IncRNAs were randomly chosen for real-time PCR validation. a The expressions of IncRNA Gm16685, Gm12250, AK151815, AK139352, and Gm8773 were significantly increased in astrocytes stimulated with Nef protein $(50 \mathrm{ng} / \mathrm{ml})$ with $0 \mathrm{~h}, 6$ h, and 12 h. b The expressions of IncRNA AK038606, Gm12326, AK039511, Gm13484, and AK043126 were markedly downregulated in astrocytes. ${ }^{*} P<0.05$, ${ }^{* *} P<0.01,{ }^{*} * P<0.001$, vs 0 h. Error bars represent means \pm SEM. These data are from three independent experiments

In our study, we found that there were 1385 upregulated lncRNAs and 734 upregulated mRNAs in the astrocytes stimulated by Nef protein for $6 \mathrm{~h}$; meanwhile, 670 IncRNAs and 876 mRNAs were downregulated. Furthermore, 1534 lncRNAs and 1077 mRNAs were upregulated, and 1271 lncRNAs and 982 mRNAs were downregulated in the astrocytes stimulated by Nef for $6 \mathrm{~h}$. Of importance, there were 638 lncRNAs and 460 mRNAs that differentially co-upregulated, and 372 lncRNAs and 376 mRNAs that differentially co-downregulated in the astrocytes treated with Nef for both $6 \mathrm{~h}$ and $12 \mathrm{~h}$. Moreover, real-time PCR assay was performed to confirm parts of differentially expressed lncRNAs and mRNAs, which was consistent with the results of lncRNAs microarray.
Interestingly, the differentially-expressed lncRNAs appear to have a relationship with the levels of inflammatory cytokines and chemokine secreted by astrocytes, suggesting that these lncRNAs might uncover novel insight into the molecular basis of HAND pathogenesis.

In our studies, a large number of inflammatory genes were significantly co-upregulated in the astrocytes treated with Nef for both $6 \mathrm{~h}$ and $12 \mathrm{~h}$, especially Cxcl11, Cxcl10, Cxcl9, Cxcl3, Cxcl2, Cxcl1, Ccl5, Il-1ß, Il-6, and Tnf. Furthermore, some mRNAs including Ifnb1, Irg1, Tnfsf10, and CD69 were also screened out and dramatically increased (Table 1), whose functions are associated with immune response, interferon (IFN) signal as well as apoptosis. Therefore, further studies 

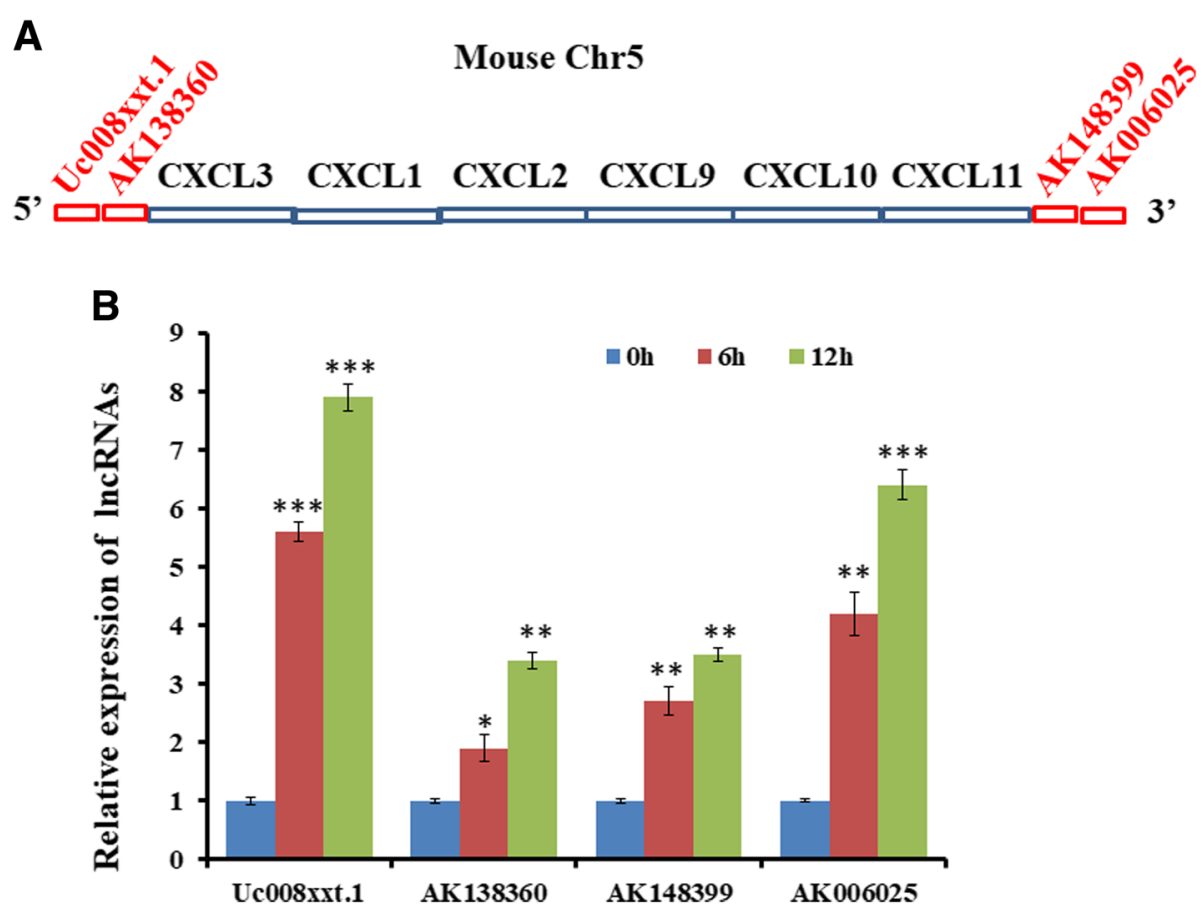

Fig. 6 Verification of IncRNA location at two terminals of CXCL9/10/11 gene cluster on the mouse chromosome 5. a Schematic diagram of IncRNA location at two terminals of CXCL9/10/11 gene cluster. $\mathbf{b}$ Real-time PCR assay detection of IncRNA expression in astrocytes treated with Nef protein $(50 \mathrm{ng} / \mathrm{ml})$ with $0 \mathrm{~h}, 6 \mathrm{~h}$, and $12 \mathrm{~h} .{ }^{*} P<0.05,{ }^{*} P<0.01,{ }^{* * *} P<0.001, \mathrm{vs} 0 \mathrm{~h}$. Error bars represent means \pm SEM. These data are from three independent experiments

are needed to demonstrate whether they are involved in HAND process.

CXC chemokine, structurally recognizable by the position of four conserved cysteine residues, are prominent mediators of chemotaxis. The Cxcl9/10/11 genes locate on the mouse chromosome 5 in cluster manner and are induced by IFN [62]. Previous data showed that Nef increased IP-10 expression in astrocytes [25]. Here, we scanned the chemokine expression profile in primary mouse astrocytes treated with Nef protein. The result showed that $\mathrm{Cxcl} 9$, Cxcl10, and $\mathrm{Cxcl} 11$ were all top differentially expressed; of importance, Nef increased CXCL9, CXCL10, and CXCL11, mRNA levels in human astrocytes, which suggests an important role in HAND pathogenesis.

Emerging data show that lncRNAs are involved in regulating NF- $\mathrm{kB}$ signaling, anti-viral response, and inflammatory response [36-39, 47]. In the present study, based on the GO term enrichment and pathway maps of mRNAs, we found that markedly enriched molecular functions and biological processes of upregulated genes in astrocytes were mainly associated with cytokine and chemokine activity as well as their receptor binding in astrocytes treated with Nef protein. These findings are consistent with previous data showing that the infiltration of immune cells and inflammation play a vital role in the pathogenesis of HAND [17].
It has been established that lncRNAs have been shown to link a number of epigenetic modified complexes with transcriptional factors including $\mathrm{NF}-\mathrm{kB}$, resulting in regulating gene expression [33, 34, 36]. In addition, lncRNAs bind CBP/P300 activity to regulate gene expression [47]. Here, we analyzed four lncRNAs located on 5 ' terminal and 3' terminal of $\mathrm{Cxcl} 3 / 2 / 1$ gene cluster and $\mathrm{Cxcl} 9 / 10 / 11$ gene cluster. Among them, AK138360 and AK006025 siRNA located on 3' terminal of the Cxcl9/10/11 gene cluster. Unexpectedly, all of Cxcl9, Cxcl10, and Cxcl11 expression were dramatically decreased in mouse astrocytes treated with Nef protein after knockdown of AK006025, not AK138360. Furthermore, RIP and ChIP assay showed that AK006025 associated with NF- $\mathrm{B}$ p65 and CBP/P300 was enriched in the promoter of $\mathrm{Cxcl} 9$, Cxcl10, and Cxcl11. These data suggest that interaction of AK006025 and CBP/P300 might regulate epigenetically $\mathrm{Cxc19/10/11}$ cluster gene transcription in HAND pathogenesis.

So far, our findings still have several limitations. First of all, these studies only were performed to scan lncRNA profiles in primary mouse astrocytes, which is possibly different from that of human astrocytes, particularly for ncRNAs that are heterogeneous expressions in mouse cells. Secondly, we only determined the role of a single acute exposure to Nef protein, which may differ from the effects of chronic exposure in HAND pathogenesis. 

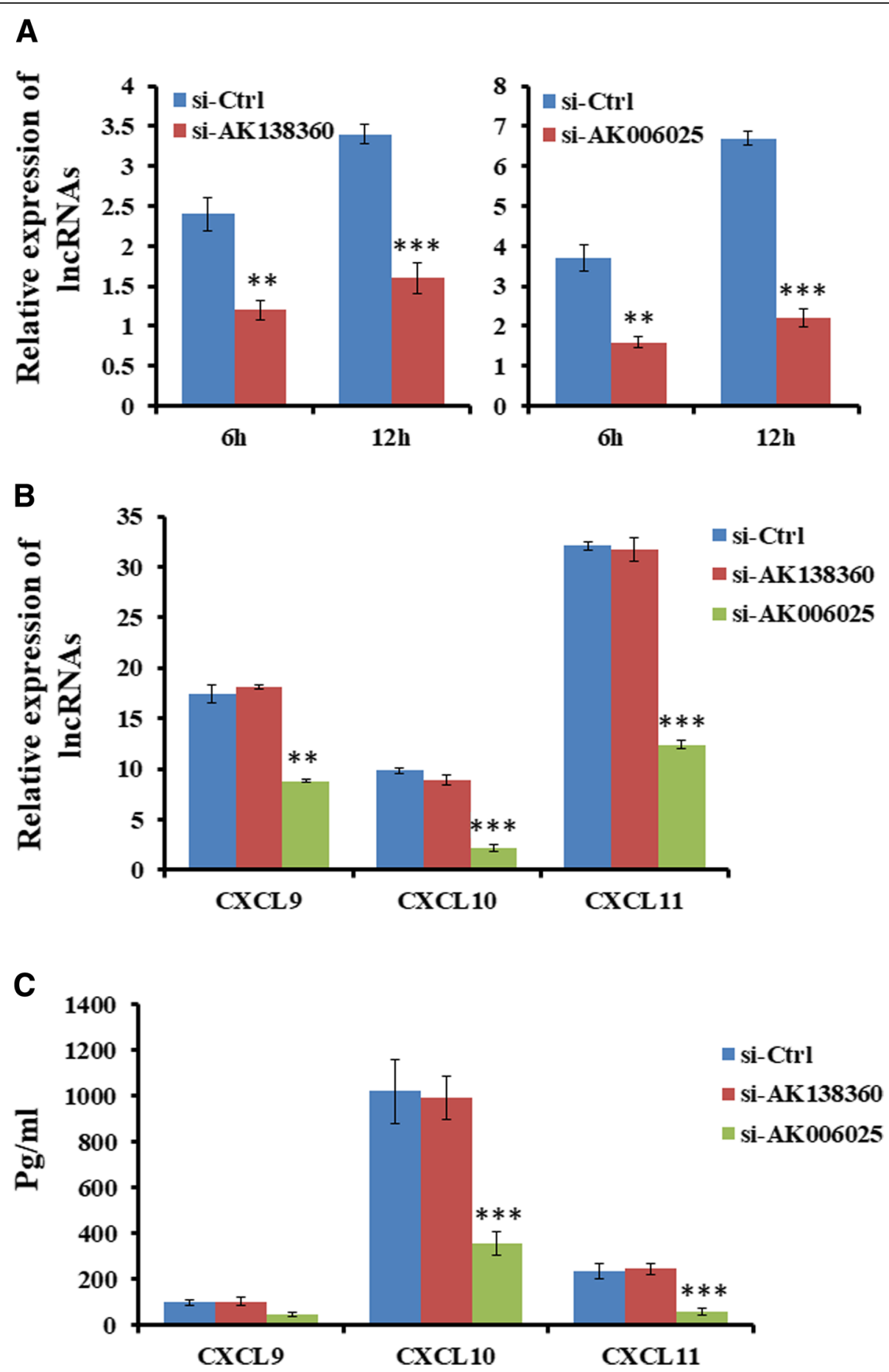

Fig. 7 Knockdown of IncRNA AK006025 reduced CXCL9/10/11 cluster gene expression in astrocytes treated with Nef. a Real-time PCR assay detection of IncRNA expression in astrocytes transfected siRNAs for $48 \mathrm{~h}$, followed by treatment with Nef protein for $6 \mathrm{~h}$ and $12 \mathrm{~h}$. b Real-time PCR assay analysis of CXCL9, CXCL10, and CXCL11 mRNA transcriptional level in astrocytes transfected siRNAs for $48 \mathrm{~h}$, followed by treatment with Nef protein for $12 \mathrm{~h}$. c ELISA analysis of CXCL9, CXCL10, and CXCL11 secretion in astrocytes transfected siRNAs for $48 \mathrm{~h}$, followed by treatment with Nef protein for $24 \mathrm{~h}$. ${ }^{*} P<0.05$, ${ }^{*} P<0.01,{ }^{*} * P<0.001$, vs 0 h. Error bars represent means \pm SEM. These data are from three independent experiments 

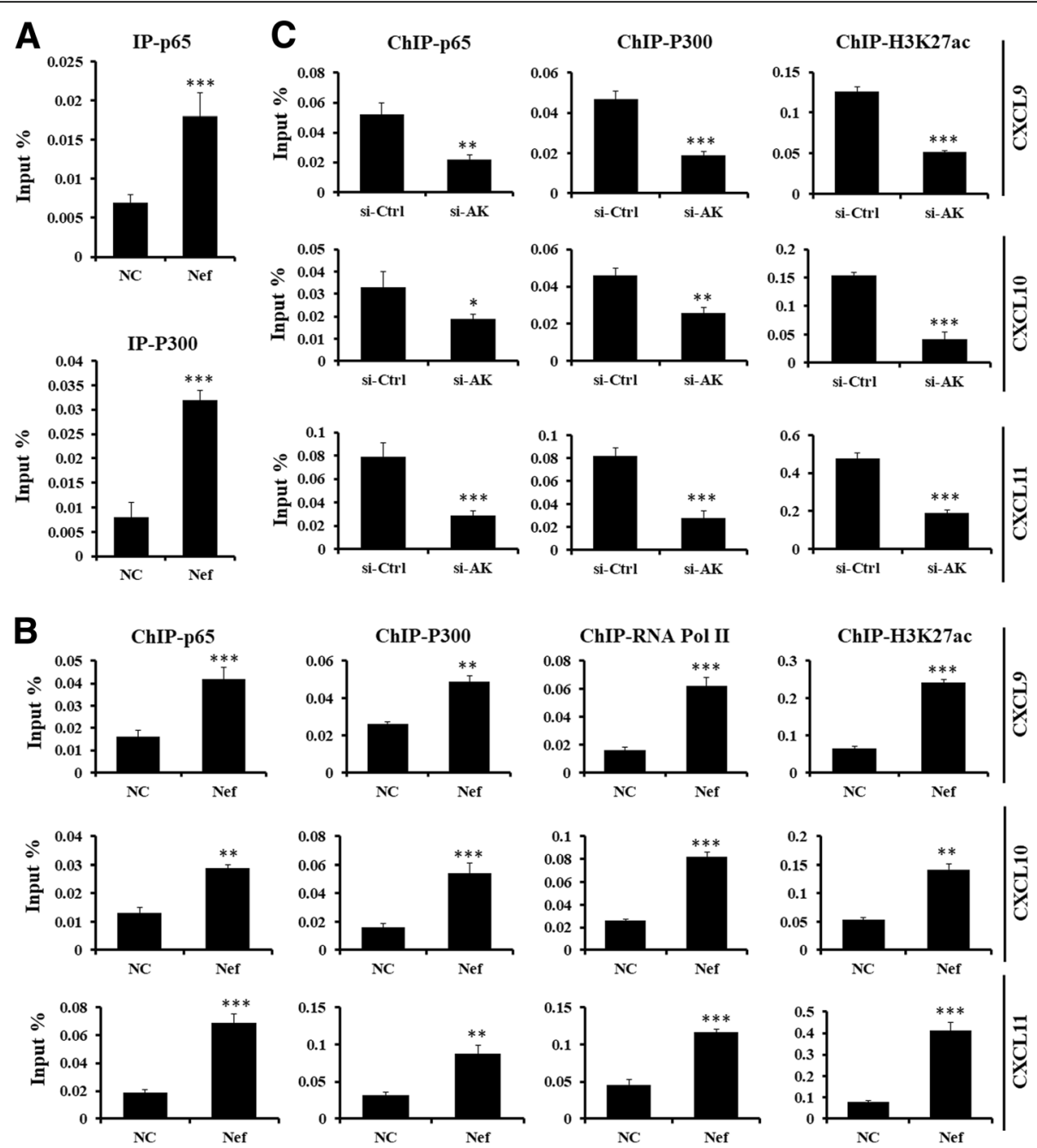

Fig. 8 Analysis of IncRNA AK006025 interaction with CBP/P300 to regulate CXCL9/10/11 cluster gene expression in astrocytes treated with Nef. a RIP assay analysis of the interaction of AK006025 with NF-KB p65 and CBP/P300 in astrocytes treatment with Nef protein for 3 h. NC: natural control. ${ }^{* *} P<0.001$, vs NC. These data are from three independent experiments. $\mathbf{b}$ ChIP assay analysis of NF-kB p65, CBP/P300, RNA Pol II, and H3K27ac enrichment on the promoter of $C X C L 9 / 10 / 11$ gene cluster in astrocytes treatment with Nef protein for $3 \mathrm{~h}$. ${ }^{* *} P<0.01,{ }^{* * *} P<0.001$, vs NC. Error bars represent means \pm SEM. These data are from three independent experiments. c ChIP assay analysis of NF-KB p65, CBP/P300, and H3K27ac enrichment on the promoter of CXCL9/10/11 gene cluster in astrocytes transfected siRNAs for $48 \mathrm{~h}$, followed by treatment with Nef protein for 3 h. si-AK: si-AK006025. ${ }^{*} P<0.05,{ }^{* *} P<0.01,{ }^{* * *} P<0.001$, vs his-Ctrl. Error bars represent means \pm SEM. These data are from three independent experiments

Therefore, it is important to demonstrate how Nef influences lncRNAs expression in human astrocytes in HAND.

\section{Conclusion}

In summary, our results revealed that Nef induced thousands of differentially expressed lncRNAs in astrocytes. LincRNA AK006025 was involved in regulating Nef-induced CXCL9, CXCL10, and CXCL11 expression through interaction with NF-kB p65 and CBP/P300, which may play key roles in neuroinflammation and pathogenesis of HAND.

\section{Additional file}

Additional file 1: Table S1. Primer sequences for real-time PCR assay. Table S2. Top 20 overlapped and downregulated IncRNAs in mouse astrocytes stimulated with Nef protein $(50 \mathrm{ng} / \mathrm{ml})$ for $6 \mathrm{~h}$ and $12 \mathrm{~h}$. Table S3. Analysis of differentially upregulated IncRNAs on the chromosome 5 in the mouse astrocytes stimulated with Nef protein $(50 \mathrm{ng} / \mathrm{ml})$ for $6 \mathrm{~h}$ and $12 \mathrm{~h}$. (DOC $118 \mathrm{~kb})$

\section{Abbreviations}

AIDS: Acquired immunodeficiency syndrome; BBB: Blood-brain barrier; CBP/ P300: CREB-binding protein; ChIP: Chromatin immunoprecipitation; CNS: Central nervous system; GFAP: Glial fibrillary acidic protein; GO: Gene ontology; HAART: Highly active antiretroviral therapy; HAD: HIV-associated dementia; HAND: HIV-associated neurocognitive disorder; HDAC1: Histone 
deacetylase 1; HIV-1: Human immunodeficiency virus type 1; L-1 $\beta$ : Interleukin-1 betta; IP-10: Interferon-gamma-inducible 10-Kd protein; IncRNAs: Long non-coding RNAs; MF: Molecular function; Nef: Negative factor; NFKB: Nuclear factor-kappa B; RIP: RNA immunoprecipitation; Tat: Transactivator of transcription; TNF: Tumor necrosis factor

\section{Acknowledgements}

We thank that his work was supported by the Qing Lan Project.

\section{Funding}

This work was supported by Jiangsu Provincial Natural Science Foundation of China (BK20141136 to Zhou and BK20151168 to Liu), Jiangsu Key Laboratory of Brain Disease Bioinformation to Zhou (jsbl1205), the National Natural Science Foundation of China (81500914 to Xue; 81372598 and 81772688 to Gao and 81700794 to Hu), Dean Special Foundation of Xuzhou Medical University (2012KJZ09 to Xue), the Graduate Innovation Program in Science and Technology of Jiangsu Province (KYLX18_2169 to Cao), and the Priority Academic Program Development of Jiangsu Higher Education Institutions (2014 PAPD).

\section{Availability of data and materials}

All data generated or analyzed during this study are included in this published article and its supplementary information files.

\section{Authors' contributions}

$F Z, X m L, D Z, L G, J W, Y Y$, and MX performed the analysis of IncRNA and mRNA profiles and real-time PCR assay. FZ, DZ, and LG performed the RIP and ChIP assay. XYL, DZ, QC, LN, and MX performed the real-time PCR verification. JW, XYL, MH, BZ, HH, and LN performed the ELISA assay and siRNA transfection. $\mathrm{FZ}, \mathrm{XmL}, \mathrm{DG}, \mathrm{KZ}, \mathrm{Yl}$, and RT conceived the design of experiments, collected and analyzed the data, and wrote the manuscript. All authors read and approved the final manuscript.

\section{Ethics approval and consent to participate}

The study was approved by the Ethical Committee for Xuzhou Medical University.

\section{Consent for publication}

Not applicable.

\section{Competing interests}

The authors declare that they have no competing interests.

\section{Publisher's Note}

Springer Nature remains neutral with regard to jurisdictional claims in published maps and institutional affiliations.

\section{Author details}

'Jiangsu Key Laboratory of Brain Disease Bioinformation, Research Center for Biochemistry and Molecular Biology, Xuzhou Medical University, Xuzhou 221004, Jiangsu, People's Republic of China. ${ }^{2}$ Jiangsu Key Laboratory of Immunity and Metabolism, Department of Pathogen Biology and Immunology and Laboratory of Infection and Immunity, Xuzhou Medical University, Xuzhou 221004, Jiangsu, People's Republic of China. ${ }^{3}$ Department of Physiology, Xuzhou Medical University, Xuzhou 221004, Jiangsu, People's Republic of China. ${ }^{4}$ Department of Neurobiology and Anatomy, Xuzhou Medical University, Xuzhou 221004, Jiangsu, People's Republic of China. ${ }^{5}$ Department of Dermatology, University of California Davis (UC Davis) School of Medicine, Sacramento, CA, USA.

Received: 8 June 2018 Accepted: 23 October 2018 Published online: 31 October 2018

\section{References}

1. Clifford DB, Ances BM. HIV-associated neurocognitive disorder. Lancet Infect Dis. 2013;13(11):976-86.

2. Ghafouri M, Amini S, Khalili K, Sawaya BE. HIV-1 associated dementia: symptoms and causes. Retrovirology. 2006;3:28.

3. Gaskill PJ, Miller DR, Gamble-George J, Yano H, Khoshbouei H. HIV, Tat and dopamine transmission. Neurobiol Dis. 2017;105:51-73.

4. Gonzalez E, Rovin BH, Sen L, Cooke G, Dhanda R, Mummidi S, Kulkarni $H_{1}$ Bamshad MJ, Telles V, Anderson SA, et al. HIV-1 infection and AIDS dementia are influenced by a mutant MCP-1 allele linked to increased monocyte infiltration of tissues and MCP-1 levels. Proc Natl Acad Sci U S A. 2002;99(21):13795-800.

5. Huang Y, Zhao L, Jia B, Wu L, Li Y, Curthoys N, Zheng JC. Glutaminase dysregulation in HIV-1-infected human microglia mediates neurotoxicity: relevant to HIV-1-associated neurocognitive disorders. J Neurosci. 2011; 31(42):15195-204

6. Spudich S. HIV and neurocognitive dysfunction. Curr HIV/AIDS Rep. 2013; 10(3):235-43.

7. Silverstein PS, Shah A, Weemhoff J, Kumar S, Singh DP, Kumar A. HIV-1 gp120 and drugs of abuse: interactions in the central nervous system. Curr HIV Res. 2012;10(5):369-83,

8. Xu C, Liu J, Chen L, Liang S, Fujii N, Tamamura H, Xiong H. HIV-1 gp120 enhances outward potassium current via CXCR4 and CAMP-dependent protein kinase a signaling in cultured rat microglia. Glia. 2011;59(6): 997-1007.

9. Shah A, Kumar A. HIV-1 gp120-mediated increases in IL-8 production in astrocytes are mediated through the NF-kappaB pathway and can be silenced by gp120-specific siRNA. J Neuroinflammation. 2010;7:96.

10. Wyss-Coray T, Masliah E, Toggas SM, Rockenstein EM, Brooker MJ, Lee HS, Mucke L. Dysregulation of signal transduction pathways as a potential mechanism of nervous system alterations in HIV-1 gp120 transgenic mice and humans with HIV-1 encephalitis. J Clin Invest. 1996;97(3):789-98.

11. Green MV, Thayer SA. NMDARs adapt to neurotoxic HIV protein Tat downstream of a GluN2A-ubiquitin ligase signaling pathway. J Neurosci. 2016;36(50):12640-9

12. Bruce-Keller AJ, Chauhan A, Dimayuga FO, Gee J, Keller JN, Nath A. Synaptic transport of human immunodeficiency virus-tat protein causes neurotoxicity and gliosis in rat brain. J Neurosci. 2003;23(23):8417-22.

13. D'Aversa TG, Yu KO, Berman JW. Expression of chemokine by human fetal microglia after treatment with the human immunodeficiency virus type 1 protein Tat. J Neuro-Oncol. 2004:10(2):86-97.

14. Kim BO, Liu Y, Ruan Y, Xu ZC, Schantz L, He JJ. Neuropathologies in transgenic mice expressing human immunodeficiency virus type 1 Tat protein under the regulation of the astrocyte-specific glial fibrillary acidic protein promoter and doxycycline. Am J Pathol. 2003;162(5):1693-707.

15. Bergonzini V, Calistri A, Salata C, Del Vecchio C, Sartori E, Parolin C, Palu G. Nef and cell signaling transduction: a possible involvement in the pathogenesis of human immunodeficiency virus-associated dementia. J Neuro-Oncol. 2009; 15(3):238-48.

16. Liu X, Shah A, Gangwani MR, Silverstein PS, Fu M, Kumar A. HIV-1 Nef induces CCL5 production in astrocytes through p38-MAPK and PI3K/Akt pathway and utilizes NF-kB, CEBP and AP-1 transcription factors. Sci Rep. 2014:4:4450.

17. Hong S, Banks WA. Role of the immune system in HIV-associated neuroinflammation and neurocognitive implications. Brain Behav Immun. 2015:45:1-12.

18. Allen NJ, Barres BA. Neuroscience: glia - more than just brain glue. Nature. 2009:457(7230):675-7.

19. Barres BA. The mystery and magic of glia: a perspective on their roles in health and disease. Neuron. 2008;60(3):430-40

20. Wilson EH, Weninger W, Hunter CA. Trafficking of immune cells in the central nervous system. J Clin Invest. 2010;120(5):1368-79.

21. Budka H, Wiley CA, Kleihues P, Artigas J, Asbury AK, Cho ES, Cornblath DR, Dal Canto MC, DeGirolami U, Dickson D, et al. HIV-associated disease of the nervous system: review of nomenclature and proposal for neuropathologybased terminology. Brain Pathol. 1991;1(3):143-52.

22. Kestler HW 3rd, Ringler DJ, Mori K, Panicali DL, Sehgal PK, Daniel MD, Desrosiers RC. Importance of the nef gene for maintenance of high virus loads and for development of AIDS. Cell. 1991;65(4):651-62.

23. Puzar Dominkus $P$, Ferdin J, Plemenitas A, Peterlin BM, Lenassi M. Nef is secreted in exosomes from Nef.GFP-expressing and HIV-1-infected human astrocytes. J Neuro-Oncol. 2017;23(5):713-24.

24. Khan MB, Lang MJ, Huang MB, Raymond A, Bond VC, Shiramizu B, Powell MD. Nef exosomes isolated from the plasma of individuals with HIVassociated dementia (HAD) can induce Abeta(1-42) secretion in SH-SY5Y neural cells. J Neuro-Oncol. 2016;22(2):179-90.

25. van Marle G, Henry S, Todoruk T, Sullivan A, Silva C, Rourke SB, Holden J, McArthur JC, Gill MJ, Power C. Human immunodeficiency virus type 1 Nef protein mediates neural cell death: a neurotoxic role for IP-10. Virology. 2004;329(2):302-18. 
26. Chompre G, Cruz E, Maldonado L, Rivera-Amill V, Porter JT, Noel RJ, Jr. Astrocytic expression of HIV-1 Nef impairs spatial and recognition memory. Neurobiol Dis 2013; 49:128-136.

27. Torres-Munoz J, Stockton P, Tacoronte N, Roberts B, Maronpot RR, Petito CK Detection of HIV-1 gene sequences in hippocampal neurons isolated from postmortem AIDS brains by laser capture microdissection. J Neuropathol Exp Neurol. 2001;60(9):885-92.

28. Mercer TR, Dinger ME, Mattick JS. Long non-coding RNAs: insights into functions. Nat Rev Genet. 2009;10(3):155-9.

29. Qureshi IA, Mehler MF. Emerging roles of non-coding RNAs in brain evolution, development, plasticity and disease. Nat Rev Neurosci. 2012; 13(8):528-41.

30. Johnson R. Long non-coding RNAs in Huntington's disease neurodegeneration. Neurobiol Dis. 2012;46(2):245-54.

31. Roberts TC, Morris KV, Wood MJ. The role of long non-coding RNAs in neurodevelopment, brain function and neurological disease. Philos Trans $R$ Soc Lond Ser B Biol Sci. 2014;369(1652).

32. Gibb EA, Vucic EA, Enfield KS, Stewart GL, Lonergan KM, Kennett JY, BeckerSantos DD, MacAulay CE, Lam S, Brown CJ, Lam WL. Human cancer long non-coding RNA transcriptomes. PLoS One. 2011;6(10):e25915.

33. Khalil AM, Guttman M, Huarte M, Garber M, Raj A, Rivea Morales D, Thomas K, Presser A, Bernstein BE, van Oudenaarden A, et al. Many human large intergenic noncoding RNAs associate with chromatin-modifying complexes and affect gene expression. Proc Natl Acad Sci U S A. 2009; 106(28):11667-72.

34. Guttman M, Donaghey J, Carey BW, Garber M, Grenier JK, Munson G, Young $G$, Lucas $A B, A$ ch $R$, Bruhn $L$, et al. lincRNAs act in the circuitry controlling pluripotency and differentiation. Nature. 2011;477(7364):295-300.

35. Wang J, Zhao H, Fan Z, Li G, Ma Q, Tao Z, Wang R, Feng J, Luo Y, Long Noncoding RNA. H19 promotes neuroinflammation in ischemic stroke by driving histone deacetylase 1-dependent M1 microglial polarization. Stroke. 2017:48(8):2211-21.

36. NE II, Heward JA, Roux B, Tsitsiou E, Fenwick PS, Lenzi L, Goodhead I, HertzFowler C, Heger A, Hall N, et al. Long non-coding RNAs and enhancer RNAs regulate the lipopolysaccharide-induced inflammatory response in human monocytes. Nat Commun. 2014;5:3979.

37. Zhou X, Han X, Wittfeldt A, Sun J, Liu C, Wang X, Gan LM, Cao H, Liang Z. Long non-coding RNA ANRIL regulates inflammatory responses as a novel component of NF-kappaB pathway. RNA Biol. 2016;13(1):98-108.

38. Zhao G, Su Z, Song D, Mao Y, Mao X. The long noncoding RNA MALAT1 regulates the lipopolysaccharide-induced inflammatory response through its interaction with NF-kappaB. FEBS Lett. 2016;590(17):2884-95.

39. Zhang F, Wu L, Qian J, Qu B, Xia S, La T, Wu Y, Ma J, Zeng J, Guo Q, et al. Identification of the long noncoding RNA NEAT1 as a novel inflammatory regulator acting through MAPK pathway in human lupus. J Autoimmun. 2016;75:96-104.

40. Barlev NA, Liu L, Chehab NH, Mansfield K, Harris KG, Halazonetis TD, Berger SL. Acetylation of p53 activates transcription through recruitment of coactivators/histone acetyltransferases. Mol Cell. 2001; 8(6):1243-54.

41. Schroder S, Herker E, Itzen F, He D, Thomas S, Gilchrist DA, Kaehlcke K, Cho S, Pollard KS, Capra JA, et al. Acetylation of RNA polymerase II regulates growth-factor-induced gene transcription in mammalian cells. Mol Cell. 2013;52(3):314-24

42. Tie F, Banerjee R, Stratton CA, Prasad-Sinha J, Stepanik V, Zlobin A, Diaz MO Scacheri PC, Harte PJ. CBP-mediated acetylation of histone H3 lysine 27 antagonizes Drosophila Polycomb silencing. Development. 2009;136(18): 3131-41.

43. Wang F, Marshall CB, Ikura M. Transcriptional/epigenetic regulator CBP/p300 in tumorigenesis: structural and functional versatility in target recognition. Cell Mol Life Sci. 2013;70(21):3989-4008.

44. Bedford DC, Kasper LH, Fukuyama T, Brindle PK. Target gene context influences the transcriptional requirement for the KAT3 family of CBP and p300 histone acetyltransferases. Epigenetics. 2010;5(1):9-15.

45. Jin Q, Yu LR, Wang L, Zhang Z, Kasper LH, Lee JE, Wang C, Brindle PK, Dent SY, Ge K. Distinct roles of GCN5/PCAF-mediated H3K9ac and CBP/p300mediated H3K18/27ac in nuclear receptor transactivation. EMBO J. 2011; 30(2):249-62.

46. Bose DA, Donahue G, Reinberg D, Shiekhattar R, Bonasio R, Berger SL. RNA binding to CBP stimulates histone acetylation and transcription. Cell. 2017; 168(1-2):135-49 e22.
47. Cui W, Yoneda R, Ueda N, Kurokawa R. Arginine methylation of translocated in liposarcoma (TLS) inhibits its binding to long noncoding RNA, abrogating TLS-mediated repression of CBP/p300 activity. J Biol Chem. 2018;293(28): 10937-48.

48. Liu XM, He FX, Pang RR, Zhao D, Qiu W, Shan K, Zhang J, Lu YL, Li Y, Wang YW. Interleukin-17 (IL-17)-induced microRNA 873 (miR-873) contributes to the pathogenesis of experimental autoimmune encephalomyelitis by targeting A20 ubiquitin-editing enzyme. J Biol Chem. 2014;289(42): 28971-86.

49. Liu X, Zhang Q, Wang W, Zuo D, Wang J, Zhou F, Niu L, Li X, Qin S, Kou Y, et al. Analysis of long noncoding RNA and mRNA expression profiles in IL-9-activated astrocytes and EAE mice. Cell Physiol Biochem. 2018;45(5): 1986-98

50. Kang Z, Altuntas CZ, Gulen MF, Liu C, Giltiay N, Qin H, Liu L, Qian W, Ransohoff RM, Bergmann C, et al. Astrocyte-restricted ablation of interleukin17-induced Act1-mediated signaling ameliorates autoimmune encephalomyelitis. Immunity. 2010;32(3):414-25.

51. Tsai MC, Manor O, Wan Y, Mosammaparast N, Wang JK, Lan F, Shi Y, Segal E, Chang HY. Long noncoding RNA as modular scaffold of histone modification complexes. Science. 2010;329(5992):689-93.

52. Zhou F, Shimoda M, Olney L, Lyu Y, Tran K, Jiang G, Nakano K, Davis RR, Tepper CG, Maverakis E, et al. Oncolytic reactivation of KSHV as a therapeutic approach for primary effusion lymphoma. Mol Cancer Ther. 2017;16(11): 2627-38.

53. Raymond AD, Campbell-Sims TC, Khan M, Lang M, Huang MB, Bond VC, Powell MD. HIV type 1 Nef is released from infected cells in CD45(+) microvesicles and is present in the plasma of HIV-infected individuals. AIDS Res Hum Retrovir. 2011;27(2):167-78.

54. Cullen BR. HIV-1 auxiliary proteins: making connections in a dying cell. Cell. 1998;93(5):685-92

55. Fujii $Y$, Otake $K$, Tashiro $M$, Adachi A. Soluble Nef antigen of HIV-1 is cytotoxic for human CD4+ T cells. FEBS Lett. 1996;393(1):93-6.

56. Qiao X, He B, Chiu A, Knowles DM, Chadburn A, Cerutti A. Human immunodeficiency virus 1 Nef suppresses CD40-dependent immunoglobulin class switching in bystander B cells. Nat Immunol. 2006;7(3):302-10.

57. Yan Q, Ma X, Shen C, Cao X, Feng N, Oin D, Zeng Y, Zhu J, Gao SJ, Lu C. Inhibition of Kaposi's sarcoma-associated herpesvirus lytic replication by HIV-1 Nef and cellular microRNA hsa-miR-1258. J Virol. 2014;88(9): 4987-5000.

58. Marecki JC, Cool CD, Parr JE, Beckey VE, Luciw PA, Tarantal AF, Carville A, Shannon RP, Cota-Gomez A, Tuder RM, et al. HIV-1 Nef is associated with complex pulmonary vascular lesions in SHIV-nef-infected macaques. Am J Respir Crit Care Med. 2006;174(4):437-45.

59. Xue M, Yao S, Hu M, Li W, Hao T, Zhou F, Zhu X, Lu H, Qin D, Yan Q, et al. HIV-1 Nef and KSHV oncogene K1 synergistically promote angiogenesis by inducing cellular miR-718 to regulate the PTEN/AKT/mTOR signaling pathway. Nucleic Acids Res. 2014:42(15):9862-79.

60. Narasipura SD, Kim S, Al-Harthi L. Epigenetic regulation of HIV-1 latency in astrocytes. J Virol. 2014;88(5):3031-8.

61. Prensner JR, lyer MK, Sahu A, Asangani IA, Cao Q, Patel L, Vergara IA, Davicioni E, Erho N, Ghadessi M, et al. The long noncoding RNA SChLAP1 promotes aggressive prostate cancer and antagonizes the SWI/SNF complex. Nat Genet. 2013;45(11):1392-8.

62. Ogawa N, Ping L, Zhenjun L, Takada Y, Sugai S. Involvement of the interferongamma-induced T cell-attracting chemokine, interferon-gamma-inducible 10kd protein (CXCL10) and monokine induced by interferon-gamma (CXCL9), in the salivary gland lesions of patients with Sjogren's syndrome. Arthritis Rheum. 2002:46(10):2730-41. 